\title{
Nano-rods oxide materials for biosensor application
}

\author{
H. A. Wahab ${ }^{1}$,I. K. Battisha ${ }^{1}$ A.A. El Saeid ${ }^{2}$ and A. A. Salama ${ }^{2}$ \\ ${ }^{1}$ Solid State Physics Department, Physics Division, National Research Center (NRC), \\ 33 Bohouth St, Dokki, Giza, ${ }^{2}$ Physics Department, El Azhar University, Cairo, Egypt
}

\begin{abstract}
RON ions selective biosensor $\left(\mathrm{Fe}^{3+}\right)$ based on zinc oxide nano-rods thin film symbolic as $\mathrm{ZnO}-(\mathrm{NRs}) \mathrm{TF}$ was develop and prepared. $\mathrm{FeCl}_{3}$ solutions with concentration ranging from $10^{-6} \mathrm{M}$ up to $10^{-2}$ Mused for studied the $\mathrm{Fe}^{3+}$ ions potentiometric response by usedZnO-(NRs)TF deposited on conducting plastic and silicon substrates as working electrodes versus reference electrode $(\mathrm{Ag} / \mathrm{AgCl})$. TheZnO-(NRs)TF was grown on conducting plastic and silicon substrates by used two methods (Sol - Gel and aqueous chemical growth (ACG)) as seed layers and nano-rod growth layer.For fabricated an advanced extracellular iron biosensor, the $\mathrm{ZnO}-(\mathrm{NRs})$ deposited on plastic and silicon substrates then coated with a thin layer of specificionophore membrane to be used for iron concentration measurements in extracellular solution. The prepared sample crystallinity and microstructure was characterized by $\mathrm{x}$-ray diffraction (XRD) which, implied that ZnO-(NRs)TF sample crystallite sizes are in the nanoscale. The prepared samples morphology was characterized by Field emission scanning electron microscope (FESEM).
\end{abstract}

Keywords: ZnO-(NRs)TF, Sol gel, aqueous chemical growth, XRD, FESEM and biosensor.

\section{Introduction}

Increasing interest in smart technologies directs our attention toward oxide materials such as $\mathrm{ZnO}$ as a possible low cost solution for energy needs. $\mathrm{ZnO}$ is gaining significant interest due to the ability to be prepared in a highly oriented manner at a low temperature, on different flexible substrates, with associated nano-structured growth and texture [1-3].

Zinc oxide $(\mathrm{ZnO})$ nano-materials such as nano-tube, nano-rods (NRs) and nano-wires have been receiving great attention, where it shows various shapes of ZnOnano-structures that can easily be synthesized by different methods and it have many valuable properties. It can be used for chemical and biological species detection. ZnO(NRs) based biosensor is one of the important potential applications. $\left(\mathrm{Fe}^{3+}\right)$ biosensor based on $\mathrm{ZnO}-(\mathrm{NRs})$ with selective iron iono-phore (18 crown 6) was reported and studied well previously by our team work and others [1]. $\mathrm{ZnO}$ has generated great interest in biosensors due to its many important properties such as being biosafe, possesses polar surface, their small size and many other properties that facilitate chemical and bio-sensing. Moreover, $\mathrm{ZnO}$ is non-toxic has electrochemical activity, chemical stability, and has high electron communication properties [4\&5].

The overall aim of this work isto fabricate an advanced extracellular iron biosensor used for iron concentration measurements in extracellular solution

\section{Materials and Methodology}

$\mathrm{ZnO}-(\mathrm{NRs}) \mathrm{TF}$ were prepared in two stage (seedsolution and nano-rod growth) by using solgel (SG) and aqueous chemical growth (ACG) methods, respectively[6\&7].

\section{Seed solution prepared by Sol-Gel method}

To obtain the desired morphology and good quality of the material, the substrate was cleaned prior to nano-crystal $\mathrm{ZnO}$ thin film deposition as reported previously by our team work [8]. The seed solution was used for the surface modification of substrate which, provides nucleation sights for the growth of nano-structures and helps to enhance the density as well as homogeneity of nano-particles[9]. A coating seed solution was prepared by dissolving zinc acetate dehydrate $\left(\mathrm{Zn}\left(\mathrm{CH}_{3} \mathrm{COO}\right)_{2} \cdot 2 \mathrm{H}_{2} \mathrm{O}\right)$ in mixed Solution of mono-ethanolamine $\mathrm{MEA}\left(\mathrm{NH}_{2} \mathrm{CH}_{2} \mathrm{CH}_{2} \mathrm{OH}\right)$ and 
2-methoxyethanol at room temperature, however the molar ratio of MEA to zinc acetate was 1:1. The seed solution was stirred at $50^{\circ} \mathrm{C}$ for $2 \mathrm{~h}$ until yielding a clear and homogeneous solution. The mixed solutions were aged at room temperature for another $24 \mathrm{~h}$. Then, the solution was coated on plastic substrate by spin coating with a speed of $3000 \mathrm{rpm}$ for $30 \mathrm{sec}$. The coating process was repeated several time and dried in open air at room temperature and finally placed in pre-heated laboratory oven at $150^{\circ}$ and $250^{\circ} \mathrm{C}$ for conducting plastic and silicon substrate, respectively in order to decompose the zinc acetate dehydrate into ZnOnano-particles. In addition the seed solution provides a good control on the alignment and density of the nucleation points that affect the diameter of the synthesized nano-structures.

\section{Growth method}

After uniformly coating substrates with $\mathrm{ZnO}$ prepared by seed layers, $\mathrm{ZnO}-(\mathrm{NRs}) \mathrm{TF}$ were grown on it using aqueous chemical growth (ACG) method at low temperature. The growth of ZnOnano-rods was achieved by immersing $\mathrm{ZnO}$ seed-layer in $150 \mathrm{~mL}$ of aqueous solution composed of $0.025 \mathrm{M}$ zinc nitrate $\left(\mathrm{Zn}\left(\mathrm{NO}_{3}\right)_{2}\right)$ and $0.025 \mathrm{M}$ hexamethylenetetramine (HMT, $\mathrm{C}_{6} \mathrm{H}_{12} \mathrm{~N}_{4}$ ) in a conventional flask. The reaction temperature was kept at $95^{\circ} \mathrm{C}$ for $6 \mathrm{~h}$. The position of the substrate inside the solution does affect much on the growth process; however, substratesare being placed in the solution with face toward the bottom of the beaker. Finally, the substrates were removed from the solution, then immediately rinsed with de-ionized water to remove any residual salt from the surface and dried in air at room temperature. The resulting $\mathrm{ZnO}-(\mathrm{NRs}) \mathrm{TF}$ structure was characterized by $\mathrm{x}$-ray diffraction (XRD) and Field emission scanning electron microscope (FESEM), respectively.

\section{Cover $\mathrm{ZnO}-(\mathrm{NRs})$ with Ionophor Membrane}

For extracellular iron ions measurements, the $\mathrm{ZnO}$-(NRs) on plastic and silicon substrates were coated with a thin layer of ionophore membrane by manual procedure. The ionophore membrane was prepared by the following composition, 18-crown-6(18CE6) [Fluka], it was used for iron ion selectivity; While Dioctylphenylphosphonate (DOPP)[Aldrich] was used as plasticizer. Polyvinylchloride (PVC) [Fluka] was used as the membrane matrix and tetrahydrofuran (THF) [Flika] was used as solvents.
After preparing the ionophore solution, the $\mathrm{ZnO}$-coated dipped two times in it for 5 minutes until a thin film of the membrane was attached to the surface of the $\mathrm{ZnO}$ coated the substrates and then drying it for $1-2$ hours at room temperature. Generally all the sensors were kept at $4^{\circ} \mathrm{C}$ when not in use. Theproposed $\mathrm{Fe}^{3+}$ sensors were used as working electrodes for the potentiometric measurements in an aqueous solution of $\mathrm{FeCl}_{3}$ with a concentration ranging from $10^{-6} \mathrm{M}$ up to $10^{-2} \mathrm{M}$. $\mathrm{An} \mathrm{Ag} / \mathrm{AgCl}$ was acting as a reference electrode. The output voltage of this experiment for each concentration of $\mathrm{FeCl}_{3}$ solution was recorded by using pHmeter (model 3510)

\section{Results and Discussion}

The crystal structure of $\mathrm{ZnO}-) \mathrm{NRs}(\mathrm{TF}$ synthesized by depositing it on the plastic substrate by using seed layers and aqueous solutions was studied through XRD as shown in Fig.1. The intensities of the peaks were measured in $2 \theta^{\circ}$ range between $30^{\circ}$ and $70^{\circ}$. The result showed that the $\mathrm{ZnO}) \mathrm{NRs}(\mathrm{TF}$ presented a strong diffraction peak at the (002) plane, seen at $2 \theta^{\circ}=34.45^{\circ}$, indicated that it is in pure wurtzite hexagonal phase with high $c$-axis orientations.

Fig. 2(a\&b) shows panoramic view images of the $\mathrm{ZnO}(\mathrm{NRs}) \mathrm{TF}$ grown on (a) plastic and (b) silicon substrates with ZnOnano-particles seed layer to provide the possible nucleation for the $\mathrm{ZnO}-(\mathrm{NRs}) \mathrm{TF}$ growth, covering the whole thin film area with uniform density, equal length, vertically aligned along the c-axis (perpendicular to the substrate) and smoothness top surface. ZnO (NRs)TF have a rod-like shape with primarily aligned along the c-axis (perpendicular to the substrate) and hexagonal cross section which is compatible with the obtained XRD results. It is distributed uniformly with an average diameter equal to (63.5 and $42 \mathrm{~nm}$ )by deposited it on both plastic and silicon substrates, respectively.We can conclude that the $\mathrm{ZnO}$ (NRs)TFdeposited on silicon substrate with seed layers prepared at $250^{\circ} \mathrm{C}$ are denser and highly oriented more than the deposited one on plastic substrate with seed layers annealed at $150^{\circ} \mathrm{C}$.

The obtained FESEM results indicated that the seed layer annealing temperature is directly influenced the ZnO (NRs)TFformation. Adjusting the nano-particles Zinc Oxide density film is a very important way to control the nano-rods diameter. 


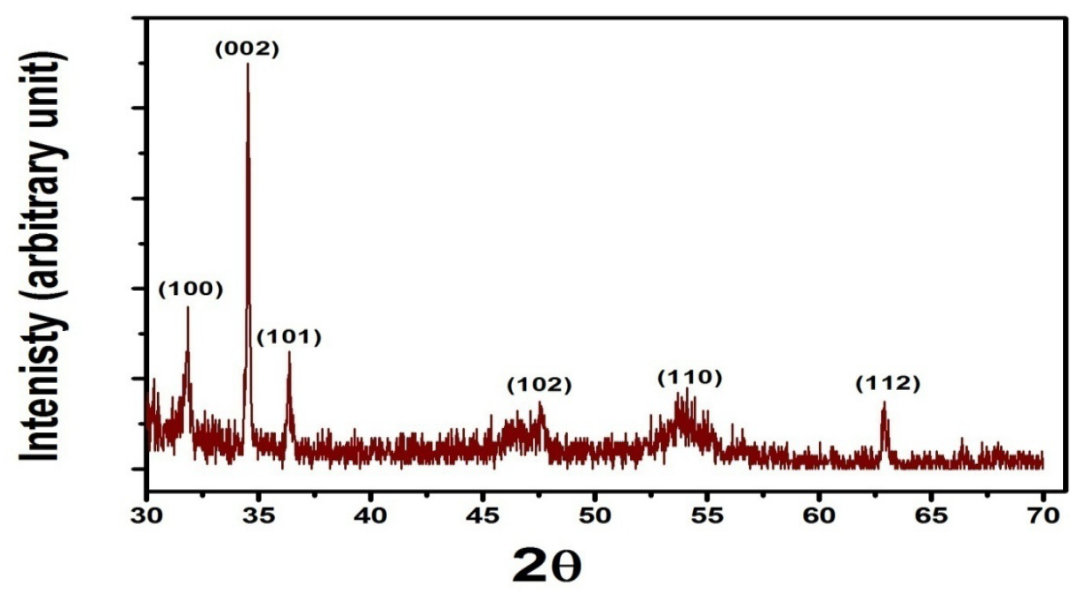

Fig. 1.x-Ray Diffraction of ZnO-(NRs)TF deposited on plastic substrate.

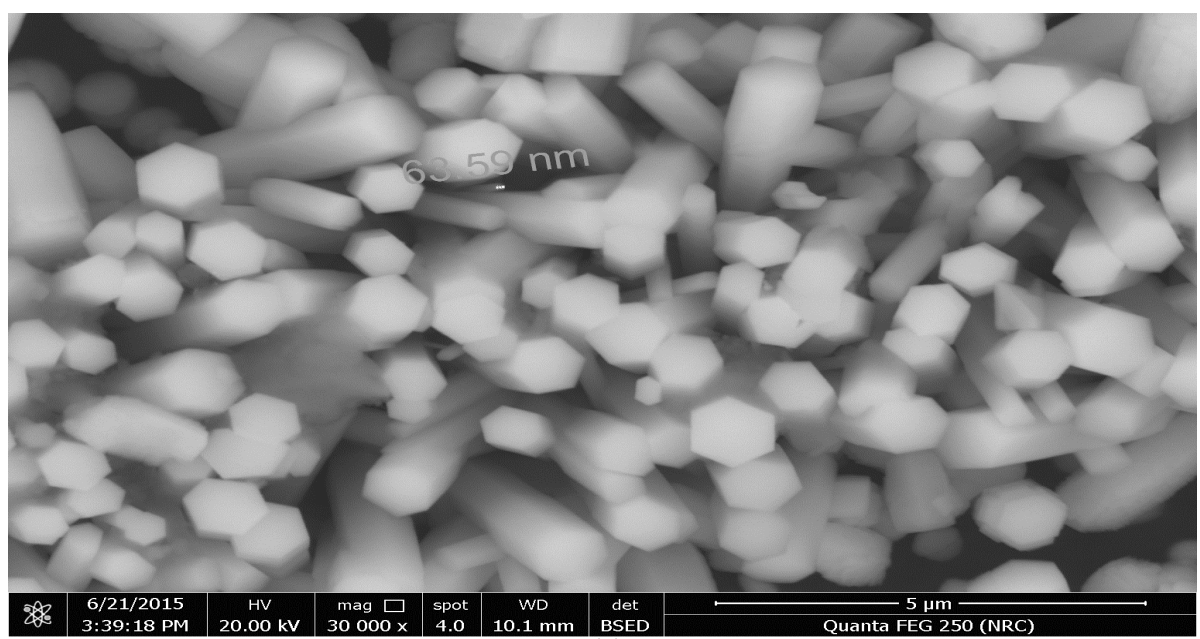

(a)

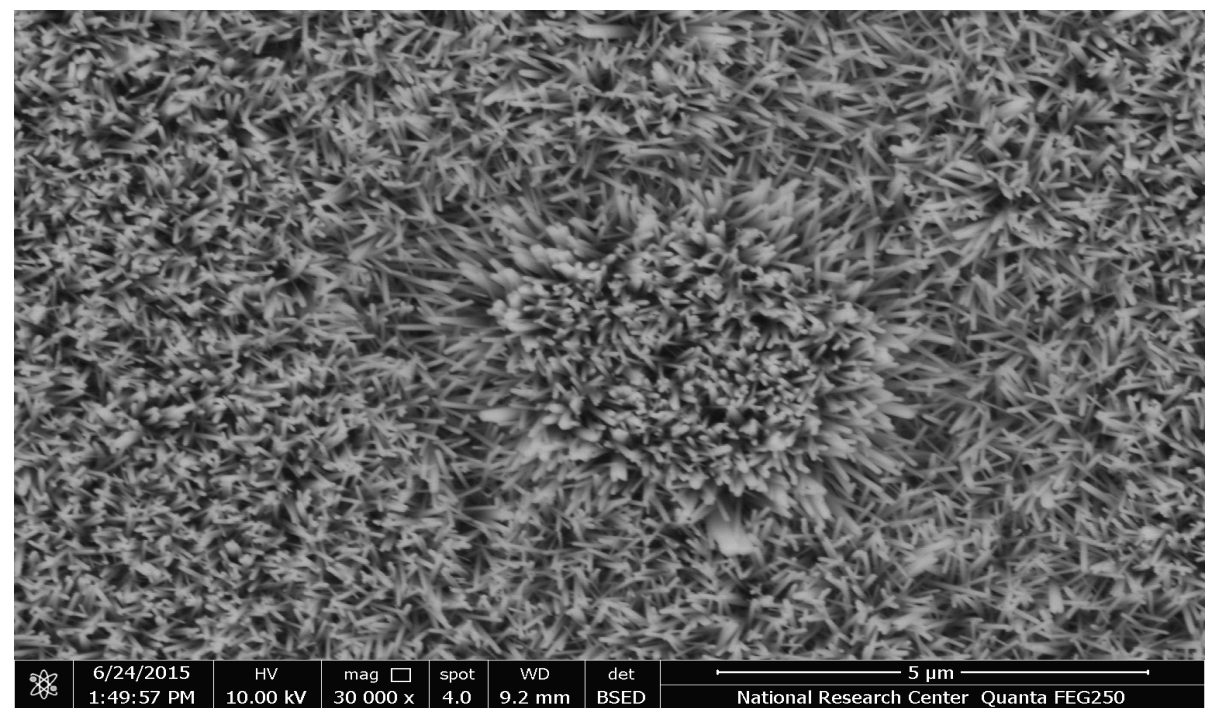

(b)

Fig.2 (a\&b). FESEM images of $\mathrm{ZnO}-(\mathrm{NRs}) \mathrm{TF}$ grown on (a) plastic substrateannealed at $150^{\circ} \mathrm{C}$ (b) siliconsubstrates annealed at $250^{\circ} \mathrm{C}$, for biosensor application. 
In fact the Zinc Oxidenano-rods diameter decreased by increasing the Zinc Oxide nanoparticles density, moreoverits orientation becomes better by increasing Zinc Oxide nanoparticles density. Where the seed solution is used for the nano-rods surface modification and helps to enhance the density as well as particles homogeneity.

ZnO-(NRs)TF deposited on the mentioned substrates, covered with iron selective membrane can be used asFe ${ }^{3+}$ biosensor to study the iron ions selectivity in an $\mathrm{FeCl}_{3}$ aqueous solutions. For this purpose $\mathrm{FeCl}_{3}$ solutions with concentration ranging from $10^{-6} \mathrm{M}$ up to $10^{-2} \mathrm{M}$ was used for studying the $\mathrm{Fe}^{3+}$ ions potentiometric response.
Fig.3 (a\&b) showsthe calibration curves for the $\mathrm{Fe}^{3+}$ ions concentration in $\mathrm{FeCl}_{3}$ solution as a function of the output voltage response by using $\mathrm{ZnO}$-(NRs)TF deposited on conducting plastic and silicon substrates covered with iron selective membrane as working elęctrodebiosensors. It is clearly seen that the $\mathrm{Fe}^{3+}$ bio-sensor output response showed stable output voltage for the mentioned concentration range.

The electrochemical cell voltage (electromotive force) changes when the tested solutions composition was changed. These changes can be related to the iron ions concentration in the test solution via a calibration procedure.

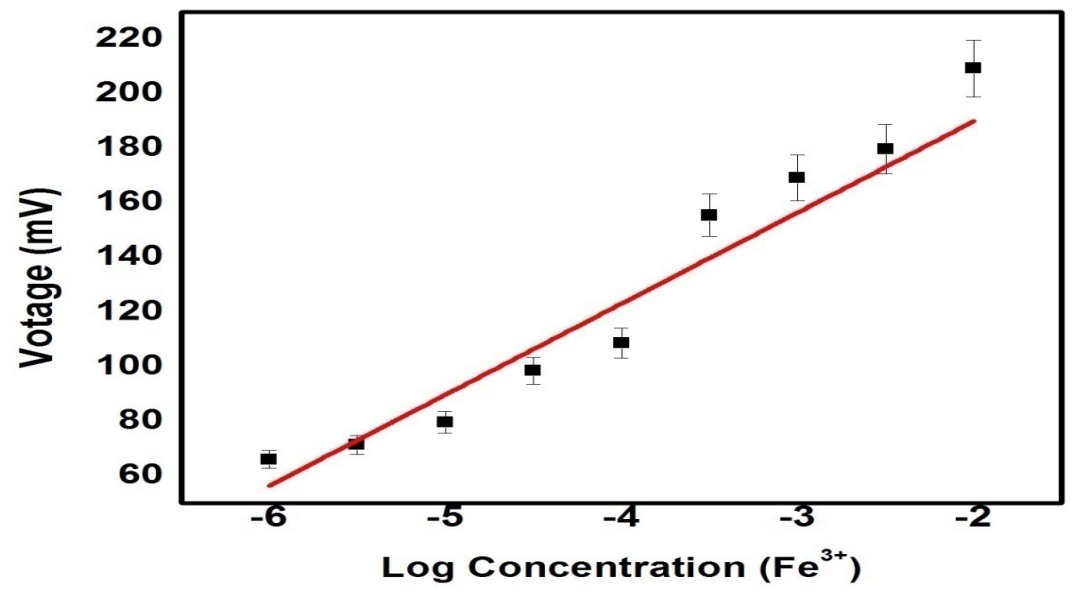

(a)

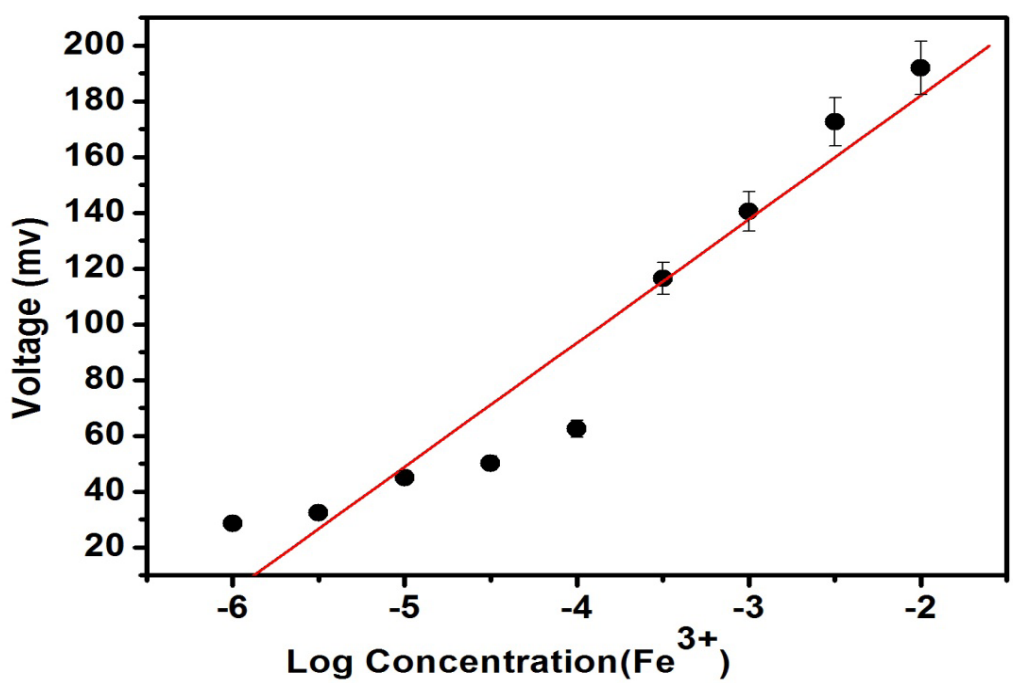

(b)

Fig.3(a\&b).The calibration curve of the log concentration for $\mathrm{Fe}^{3+}$ ionsin $\mathrm{FeCl}_{3}$ solution as a function of electrochemical potential difference by using $\mathrm{ZnO}$-(NRs)TF deposited on(a)conducting Plastic substrate (b) silicon substrate, for bio-sensor application. 
A function of the iron ions concentration is a cell voltage in the testing solution. We tested the twoselective $\mathrm{Fe}^{3+}$ biosensors in $\mathrm{FeCl}_{3}$ concentrations ranging from $10^{-6} \mathrm{M} \mathrm{up}$ to $10^{-}$ ${ }^{2} \mathrm{M}$ of iron electrolytic solution.

The cell potential construction of the tow $\mathrm{Fe}^{3+}$ biosensors using $\mathrm{ZnO}-(\mathrm{NRs}) \mathrm{TF}$ deposited on conducting plastic and silicon substrates are presented in the following schemes:

Plastic|ZnO|membrane || $\mathrm{FeCl}_{3}$ electrolyticsolution $\|$

$$
\mathrm{Cl}-|\mathrm{AgCl}| \mathrm{Ag}^{3}
$$

Silicon $|\mathrm{ZnO}|$ membrane || $\mathrm{FeCl}_{3}$ electrolyticsolution| $|\mathrm{Cl}-| \mathrm{AgCl} \mid \mathrm{Ag}$

The iron ion biosensorshavelinearrity for a wide concentration range between $10 \mathrm{M}$ and 10 $\mathrm{M}$ in both biosensors used. The results indicated that the electrode is very sensitive to iron ions giving a slope around 38.16 and $44.39 \mathrm{mV} /$ decade with a regression coefficient $\mathrm{R}=0.96$ and 0.93 for plastic and silicon working electrodes iron biosensors, respectively.

\section{Conclusion}

The two methods, Sol-Gel and aqueous chemical growth were successfully used in $\mathrm{ZnO}$ (NRs) thin films synthesis with Wurtzite hexagonal structure as revealed from XRD analysis. The $\mathrm{ZnO}$ (NRs)TF grown on conducting plasticand siliconsubstrates were found to be distributed uniformly and vertically aligned with diameter $63.5 \mathrm{~nm}$ for the former and 42 $\mathrm{nm}$ for the later. The overall aim of using the $\mathrm{ZnO}-(\mathrm{NRs}) \mathrm{TF}$ is to introduce a new advanced biosensors technique accurate, easily, faster and sheep by using the nanotechnology to act as iron biosensors for iron ions concentrations measurement.

Acknowledgement: This research was performed in the framework of; the Science \& Technology Development Fund (STDF) project ID 6358, entitled; Title: Growth of Zinc Oxide ( $\mathrm{ZnO})$ nanorods thin film for biosensor applications.

\section{Reference}

1. Battisha, I.K, Wahab, H A, Salama A A., El Saeid A.A, Willander M and Nur O,2015"Semiconductor ZnO Nano-rods Thin Film Grown On Silver Wire For Hemoglobin Biosensor Fabrication", New Journal of Glass and Ceramics (NJGC), 5, 9-15,
2. SP.Tiwari, MK Mahata, K Kumar, VK Rai, 2015"Enhanced temperature sensing response of upconversion luminescence in $\mathrm{ZnO}-\mathrm{CaTiO} 3$ : $\operatorname{Er}(3+) / \mathrm{Yb}(3+)$ nano-composite phosphor". Spectrochimicaacta Part A, Molecular and biomolecular spectroscopy.150, 623-30.

3. Wu M, Ding W, Meng J, Ni H, Li Y, Ma Q, 2015 "ElectrocatalyticBehavior of Hemoglobin Oxidation of Hydrazine Based on $\mathrm{ZnO}$ Nano-rods with Carbon Nanofiber Modified Electrode". Analytical sciences: the international journal of the Japan Society for Analytical Chemistry.;31(10),1027-33.

4. Wu M, Ding W, Meng J, Ni H, Li Y, Ma Q, 2015"ElectrocatalyticBehavior of Hemoglobin Oxidation of Hydrazine Based on $\mathrm{ZnO}$ Nano-rods with Carbon Nanofiber Modified Electrode". Analytical sciences: the international journal of the Japan Society for Analytical Chemistry.;31(10), 1027-33.

5. Ali S U., Ibupoto Z.H., Salman S., Nur O., Willander M. and Danielsson B. 2011 Selective Determination of Urea Using Urease Immobilized on $\mathrm{ZnO}$ Nanowires. Sensors and Actuators B: Chemical, 160, 637-643.

6. Ali S.U., Kashif M., Ibupoto Z.H., Alam F., Hashim U. and Willander M. 2011 Functionalised Zinc Oxide Nanotube Arrays as Electrochemical Sensors for the Selective Determination of Glucose. Micro \& Nano Letters, 6, 609-613.

7. Dev A., Panda S.K., Kar S., Chakrabarti S. and Chaudhuri S. 2006, Surfactant-Assisted Routeto Synthesize Well- Aligned ZnONanorod Arrays on Sol-Gel-Derived ZnO Thin Films. The Journal of Physical Chemistry B, 110, 14266- 14272.

8. Wahab H A., Nur O., Willander M., Salama A.A., El Saeid A.A. and Battisha I.K. (2014) Growth of Zinc Oxide ( $\mathrm{ZnO}$ ) Nano-Rod Thin Film for Hemoglobin Biosensor Applications Prepared Using Sol-Gel and Aqueous ChemicalGrowth. International Journal of Engineering and Innovative Technology (IJEIT), 4, 6-13.

9. Kim Y H., Baek N S., Kim K H and Jung S D. 2012, Simplifying Patterning Process of $\mathrm{ZnO}$ Nanowires by One Step Development and Etching Process. Journal of Sol-Gel Science and Technology, 64, 304-308.

(Received 7 / 8/2018; accepted 18/10/2018)

Egypt. J. Biophys. Biomed. Engng. Vol. 19 (2018) 


\section{القضبان النانو مترية من أكاسيد المواد واستخدامها لتطبيقات الاستشعار الحيوية.

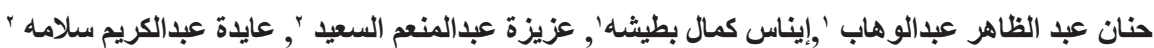

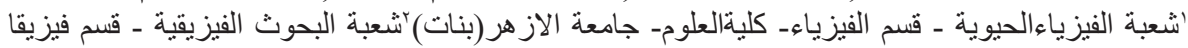 الجوامدـ المركز القومي للبحوث_مصري.}

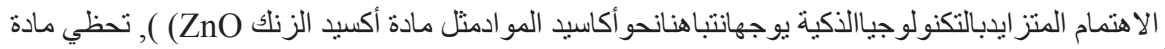

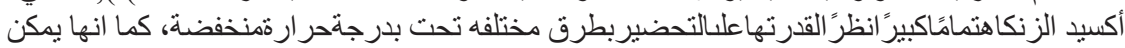

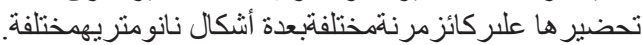

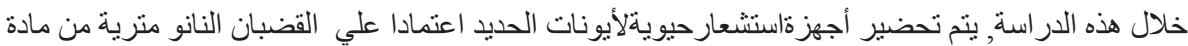

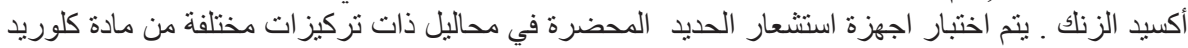

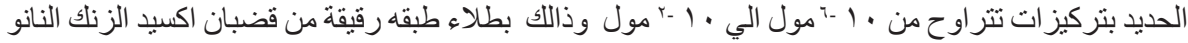

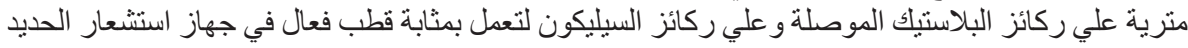
مقابل قطب كلوريد الفضة المرجعي.

ـ يتم تحضير قضبان اكسيد الزنكا النانومترية باستخدام طريقتي السائل الجيلاتيني و النمو الكميائي المائي,

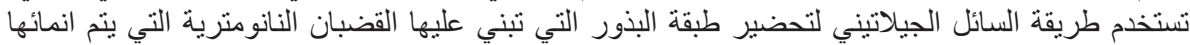
بطريقة النمو الكميائي المائي.

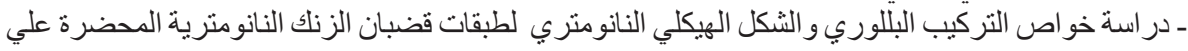

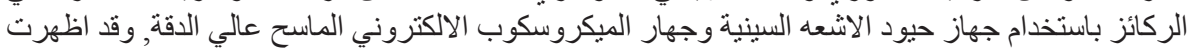

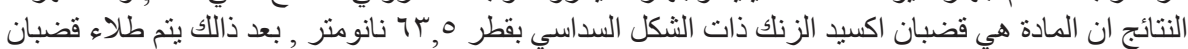

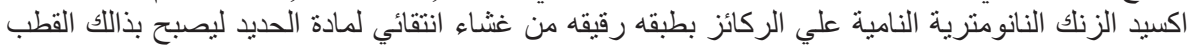

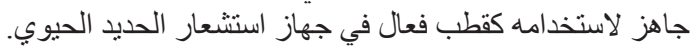

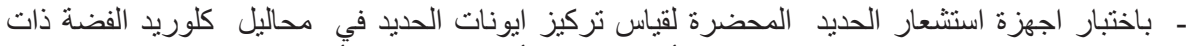

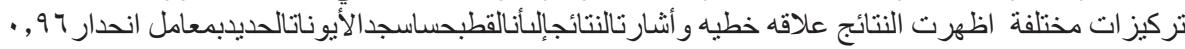

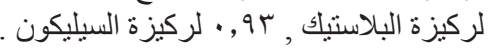

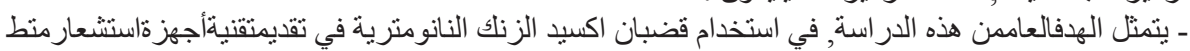

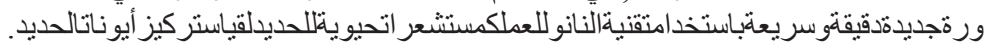

